\title{
Numerical implementation of a non local criterion to describe the failure of laminates with stress concentrations
}

\author{
Stéphanie Miot - Christian Hochard - Noël Lahellec
}

LMA, 31 chemin Joseph-Aiguier, F-13402 Marseille cedex 20

hochard@lma.cnrs-mrs.fr

ABSTRACT. A non local ply scale criterion was previously developed for predicting the failure of balanced woven ply structures with stress concentrations. This non local criterion was based on the mean values determined over a Fracture Characteristic Volume (FCV). A behavioural model was developed from a classical Continuum Damage Mechanics (CDM) model. The FCV approach and the CDM behavioural model were implemented in ABAQUS and applied to the case of unbalanced woven ply. Comparisons are made between the experimental data and the modelling predictions obtained on plates with open holes, notches and saw cuts. The numerical implementation of this approach is studied in this paper.

RÉSUMÉ. Un critère non local défini à l'échelle du pli a été développé pour prévoir la rupture de structures composites constituées de plis tissés équilibrés. Cette approche non locale est basée sur le calcul d'une quantité moyenne sur un volume caractéristique de rupture. Un modèle de comportement a été développé à partir d'un modèle classique basé sur la mécanique de l'endommagement. L'approche non locale et le modèle de comportement ont été implémentés dans ABAQUS et appliqués pour des stratifiés constitués de plis tissés déséquilibrés. Des comparaisons entre les données expérimentales et les prévisions numériques ont été réalisées dans le cas de plaques trouées et avec encoches. L'implémentation numérique de l'approche est étudiée dans ce papier.

KEYWORDS: laminate, stress concentrations, damage mechanics, finite element analysis.

MOTS-CLÉS : stratifié, concentrations de contraintes, mécanique de l'endommagement, analyse éléments finis.

DOI:10.3166/EJCM.19.89-104 @ 2010 Lavoisier, Paris

EJCM - 19/2010. Giens 2009, pages 89 to 104 


\begin{tabular}{|c|c|c|c|}
\hline \multicolumn{4}{|c|}{ Nomenclature } \\
\hline CDM & Continuum Damage Mechanics & $Y_{d_{1}}$ & $\begin{array}{l}\text { thermodynamic force associated with } \\
d_{1}\end{array}$ \\
\hline FCV & Fracture Characteristic Volume & $Y_{d_{2}}$ & $\begin{array}{l}\text { thermodynamic force associated with } \\
d_{2}\end{array}$ \\
\hline $\mathrm{d}_{1}$ & damage in the fibre direction & $Y_{d_{12}}$ & $\begin{array}{l}\text { thermodynamic force associated with } \\
d_{12}\end{array}$ \\
\hline $\mathrm{d}_{2}$ & damage in the transverse direction & $Y_{d_{1}}^{\max }$ & ultimate thermodynamic forces \\
\hline$d_{12}$ & damage in the shear direction & $Y_{0}$ & threshold of the force \\
\hline$\sigma_{1}$ & stress in the fibre direction & $\begin{array}{l}\mathrm{a}, \mathrm{b}, \mathrm{c} \\
\mathrm{m}, \mathrm{n}\end{array}$ & coefficients of tension/shear coupling \\
\hline$\sigma_{2}$ & stress in the transverse direction & $\tilde{\sigma}_{12}$ & effective stress in the shear direction \\
\hline$\sigma_{12}$ & stress in the shear direction & $\tilde{\varepsilon}_{12}^{p}$ & $\begin{array}{l}\text { effective inelastic strain in the shear } \\
\text { direction }\end{array}$ \\
\hline$E_{1}^{0}$ & $\begin{array}{l}\text { initial Young Modulus in the fibre } \\
\text { direction }\end{array}$ & $\varepsilon_{12}^{p}$ & inelastic strain in the shear direction \\
\hline$E_{2}^{0}$ & $\begin{array}{l}\text { initial Young Modulus in the } \\
\text { transverse direction }\end{array}$ & $\mathrm{X}$ & coefficient of the inelastic strain law \\
\hline$G_{12}^{0}$ & initial Shear Modulus & $\mathrm{R}_{0}$ & inelastic strain threshold \\
\hline $\mathrm{Y}_{\mathrm{eq}}$ & equivalent thermodynamic force & & \\
\hline
\end{tabular}

\section{Introduction}

Fracture in composite materials involves several mechanisms operating on various scales (Ladevèze, 1992; Wang, 1987; Reifsnider, 1998), such as matrix cracking, fibre/matrix debonding, transverse failure, delamination and fibre rupture mechanisms. Woven ply laminates show good resistance to delamination, and any transverse cracks in the yarns are stopped by the weave. In addition, it has been established experimentally that these phenomena do not usually lead to the failure of the ply, contrary to what occurs in the case of fibre ruptures. Experimental findings have shown that the first failure of a ply in the fibre direction leads to the failure of the laminate and the structure, at least under static loading conditions.

The first model we developed based on Continuum Damage Mechanics (CDM) described the mean transverse cracks across the ply, and a local ply scale criterion in the fibre direction was implemented in a FEM code (Hochard et al., 2000; Bordreuil et al., 2004). Numerical simulations were compared with experimental data in the case of plates with an open hole subjected to tensile loading. In the case of laminates showing a high level of damage $\left(\left[45^{\circ}\right]\right)$ and rupture due to structural instabilities, these comparisons showed that the model was valid, but in the case of sequences showing brittle behaviour $\left(\left[0^{\circ}\right]\right)$, the fracture was underestimated by the simulation. To describe the rupture of structures with high stress concentrations, we therefore presented in (Hochard et al., 2007) a non local criterion based on the mean values 
determined over a characteristic ply scale volume, the Fracture Characteristic Volume (FCV), corresponding to a cylinder with the thickness of the ply under investigation and a circular section of a few square millimetres. The efficiency of the FCV approach was established in the case of plates with high stress concentrations for balanced woven ply laminated structures (Hochard et al., 2009) and unbalanced woven ply laminated structures (Miot et al., 2009).

In this paper, the FCV approach and the CDM behavioural model for an unbalanced ply are presented. Here, we focused on the numerical implementation of the approach. The method was applied to unbalanced woven ply laminates reinforced with glass fibres. Comparisons between the experimental and modelling data obtained on plates with notches and saw cuts show the efficiency of this approach, even in the case of structures with high stress concentrations.

\section{Non local approach to describe the failure}

In (Hochard et al., 2007), it was observed that using a local criterion to describe the ply failure in the fibre direction leads to underestimating the force at failure 1.5fold in the case of quasi-isotropic laminated structures (plates with an open hole). In (Hochard et al., 2009), measurements of the strain fields based on the Digital Image Correlation method (Périé et al., 2009) showed the presence of strain gradients near the notches, in the case of laminates consisting of Carbon/Epoxy balanced woven ply. To account for the effects of these strain gradients on the failure of the laminate, we introduced a non local failure criterion based on the mean values obtained over a characteristic volume defined on the ply scale, the Fracture Characteristic Volume (FCV). The choice of this FCV instead of the more conventional characteristic length adopted by Withney and Nuismer (1976) is consistent with the experimentally observed fracture zone, corresponds to a material parameter, and makes it possible to avoid the usual numerical problems. The validity of this approach was confirmed in the case of various laminates consisting of Carbon/Epoxy balanced woven ply (Hochard et al., 2009) and Glass/Epoxy unbalanced woven ply (Miot et al., 2009). The non local approach is first recalled.

\subsection{Strain gradient near a notch}

Experimental findings were obtained on a plate $(300 \times 45 \times 2.5 \mathrm{~mm})$ consisting of a Glass/Epoxy unbalanced woven ply with an open hole $(\varnothing 13 \mathrm{~mm})$. Tension loading was applied to the plate. Using the Digital Image Correlation (DIC) method (Périé et al., 2009), the strain field was measured near the hole. In order to reduce the effects of noise especially that due to changes of brightness occurring during the test, and to obtain sufficiently accurate measurements, the window size and the step size used to correlate the image were set at 32 pixels. Since the specimen was a Quasi-Isotropic laminate $[0,-45,+45,90]_{\mathrm{s}}$, the ply at the surface was oriented at $0^{\circ}$. The strain field measured corresponded to an applied force of $15.7 \mathrm{kN}$. The failure occurred at an applied force of $17 \mathrm{kN}$. The measurements are presented in Figure 1, which shows a 
high strain gradient. The strain level can be seen to have reached 3\% near the hole. In a homogeneous tension test performed on a $0^{\circ}$ specimen, the strain at failure was found to be around $2.4 \%$. Locally, the strain therefore reached higher values than the strain at failure without inducing the failure of the laminate.

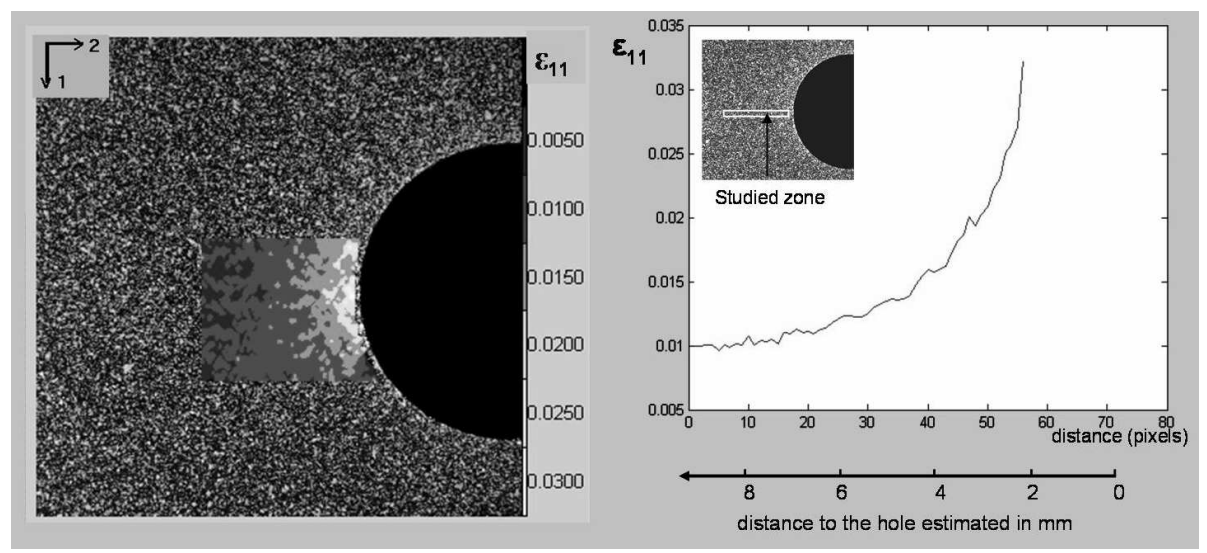

Figure 1. Strain field measured on a QI laminate under tension load (direction 1) (Applied force $=15.7 \mathrm{kN}$, Force at failure $=17 \mathrm{kN}$ )

This situation was previously studied by Whitney and Nuismer (Whitney et al., 1976), who proposed the two well-known Point Stress and Average Stress Methods. However, these methods are not easy to use, especially because the characteristic length depends on the material as well as on the geometry of the specimen. We therefore developed an approach based on a Fracture Characteristic Volume, which will be presented below.

\subsection{A ply scale characteristic volume}

The method proposed here for studying any laminate was based on a non local criterion involving a characteristic ply scale volume $V=h S$ (Figure 2), where $h$ corresponds to the thickness of the ply and the in-plane area $S$ depends on the mesostructure of the material. A circular area was adopted: the circle is the easiest shape to define, since it can be characterized simply by its diameter $d$. In addition, it is not necessary to define the direction, as in the case of a length, for example. The relevance of this choice was previously established in the context of balanced woven ply (Hochard et al., 2007; 2009) and will also be confirmed here with other types of ply. All that is required is therefore to identify the diameter $d$, which is specific to the material.

Average values can be calculated over this volume, and fracture criteria can be defined. For example, the simple criterion based on the maximum 
strain $\varepsilon_{i j}<\varepsilon_{i j \max }$ is replaced by the maximum mean strain calculated on the $F C V$ $\bar{\varepsilon}_{i j}=\frac{1}{V} \int_{V} \varepsilon_{i j} \cdot d V$ and $\bar{\varepsilon}_{i j}<\varepsilon_{i j}$ max . Any criterion can be used here such as a maximum stress/strain/damage criterion, or a more complex criterion such as the Tsai criterion.

In this study, we have chosen to use the following criterion to describe the ply failure in the fibre direction (Hochard et al., 2009):

$$
\overline{Y_{d_{1}}}=\frac{\left(\frac{1}{V} \int_{V}\left\langle\sigma_{1}\right\rangle_{+} \cdot d V\right)^{2}}{2 E_{1}^{0}} \text { and } \overline{Y_{d_{1}}}<Y_{d_{1}}^{\max }
$$

$Y_{d_{1}}^{\max }$ is the parameter defining the ultimate force in the fibre direction.

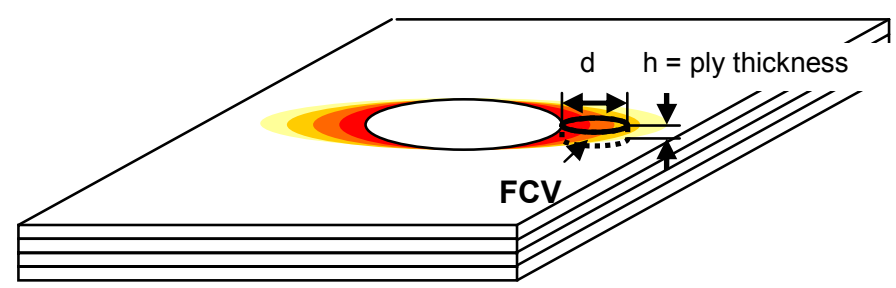

Figure 2. Non local criterion based on a Fracture Characteristic Volume (FCV)

Criterion [1] is equivalent to a mean stress criterion over the volume $V$. Stresses are averaged on the FCV and failure will occur if the average force $\overline{Y_{d_{1}}}$ reaches a maximum value. If the criterion is met, the ply and the laminate are assumed to be broken. Actually, experimental observations let appear that the failure of fibres has catastrophic effects on both the ply and the structure.

Parameters defining the failure criterion were identified in a test performed on a homogenous specimen. To determine the diameter $d$, only one test needs to be performed on a structure, such as a tension test on a $\left[0^{\circ}\right]$ plate with an open hole. The process of identification also requires performing structure computations to compare the experimental and simulated data. The FCV criterion can then be easily applied anywhere in the structure, with any laminate and any geometry.

\subsection{Implementation in ABAQUS}

Since the non local criterion based on a Fracture Characteristic Volume (FCV) has to be determined in a post-computational step after each step in the incremental calculation, an URDFIL routine was used. This routine gives the stresses, strains and 
internal variables resulting from the calculation increment at each Gauss Point. An FCV is associated with each integration point on the structure in order to obtain an intrinsic criterion. Average quantities are calculated at each FCV and the failure criterion is compared with the mean values obtained. The computation is stopped when the failure criterion is reached with an FCV if a First Ply Failure Criterion has been adopted. The Figure 3 summarizes the URDFIL working.

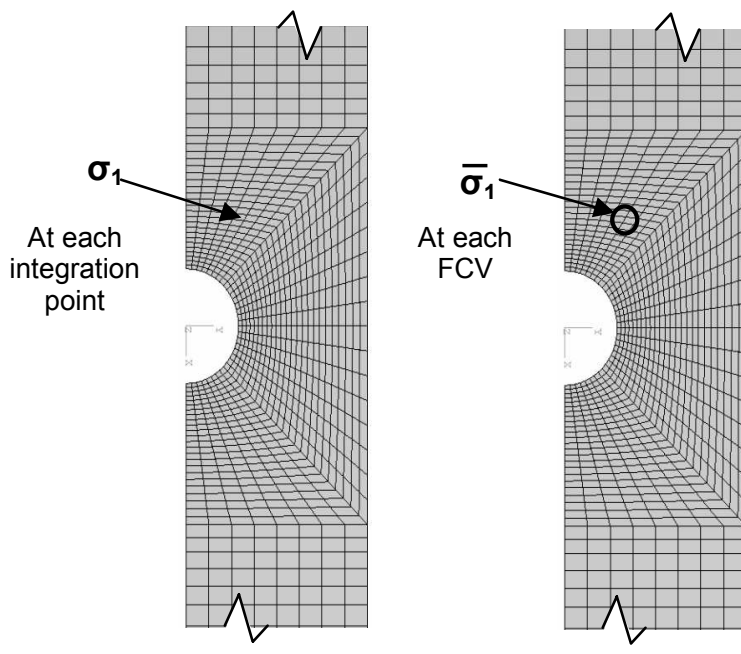

After each step in the incremental calculation

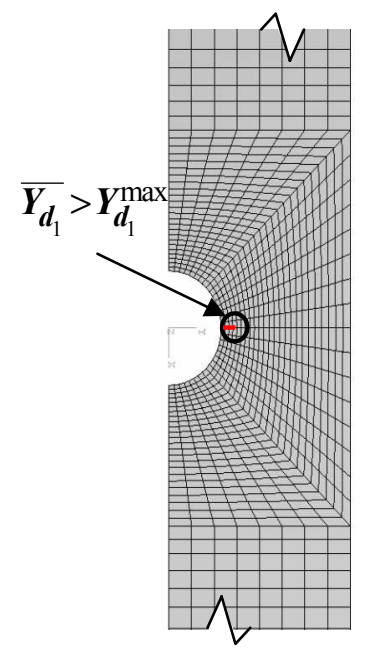

Failure of laminate

Figure 3. Non local approach in Abaqus

In the integration procedure, it is necessary to take some precautions on the border of the part. In order to avoid having to deal with an incomplete FCV located on an edge and therefore crossed by the edge, we tested the total volume of the FCV calculated from the volume of each integration point present in the FCV. This calculated volume had to be at least equal to the theoretical volume $V_{F C V} \geq \frac{\pi d^{2} h}{4}$.

The size of the mesh must be smaller than the zone in which the mean value is calculated. In a previous study (Hochard et al., 2007), it was observed that even in the high stress gradient zones around ten Gauss points in the FCV are required.

The implementation in ABAQUS is restricted to plates subjected to tension loads in the framework of laminated plate theory (the strains are taken to be homogeneous over the thickness), and only one Gauss Point is therefore required in the ply thickness.

The combination between the non local approach describing the failure in the fibre direction and a linear elastic law governing the behaviour works well in the case of the quasi-isotropic laminates widely used in industry. However, with some 
laminates, such as those subjected to combined loads on the ply scale, the damage of the material cannot be neglected. A CDM model was therefore developed and implemented in Abaqus using a UMAT routine.

\section{Continuum damage mechanics modelling of unbalanced woven ply}

A continuum damage mechanics (CDM) model was developed for predicting the behaviour of unbalanced woven ply laminates under static loading conditions (Thollon et al., 2009). This model is based on a classical damage model (Ladevèze, 1992) initially developed for UD plies. Let us briefly recall the CDM model principles originally developed in the case of tensile loading.

\subsection{Assumption}

The CDM model describes the mechanical behaviour of a material on the ply scale. In order to obtain a general model, the ply modelled here is a UD ply. In the case of woven ply, the behaviour is assumed to be the same as that of a $[0,90]$ laminate consisting of two identical UD plies. This simplified numerical approach allows to reduce the number of parameters to identify. Figure 4 gives the example of an unbalanced woven ply with $\delta \%$ fibres in the warp direction and (100- $\delta$ ) \% fibres in the weft direction. The ply is modelled in the form of two UD plies, the first of which is oriented at $0^{\circ}$ and has a thickness amounting to $\delta \%$ of the whole woven ply thickness; the second ply which is oriented at $90^{\circ}$, has a thickness corresponding to $(100-\delta) \%$ of the whole thickness.

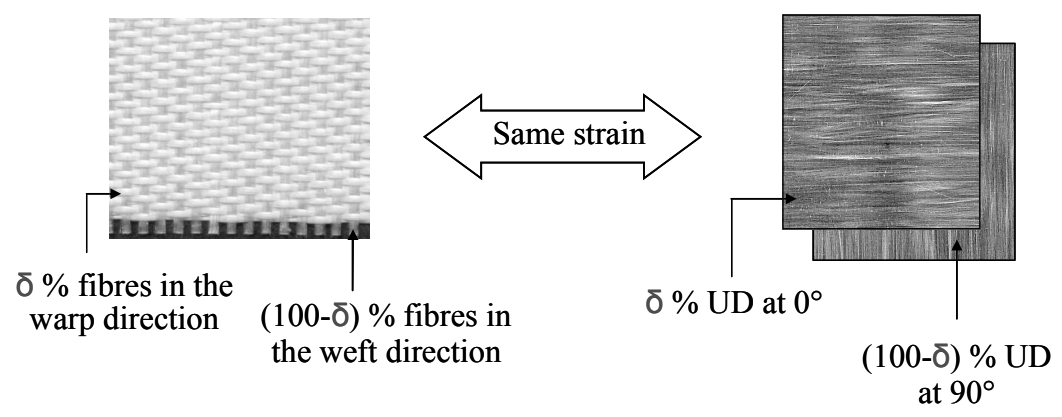

Figure 4. Assumption of the model based on the CDM

\subsection{Behaviour of UD ply up to failure}

In the fibre direction, the UD ply shows linear elastic behaviour in response to tension loading. In the transverse direction, the behaviour is non linear due to the damage. Damage takes the form of small cracks running parallel to the fibre 
direction, and leads to a loss of stiffness. When a shear load is applied (during a tensile test on a $[45]_{\mathrm{n}}$ laminate, for example), a decrease in the shear modulus and an inelastic strain are observed.

The damage kinematics are accounted for in this model in terms of the following three internal damage variables (Ladevèze et al., 2000; 2001): the brittle fracture of fibres $\mathrm{d}_{1}$, and the decrease in the stiffness resulting from transverse and shear loading, which is denoted $\mathrm{d}_{2}$ and $\mathrm{d}_{12}$, respectively. Under tension loading conditions, $d_{1}$ has to develop suddenly in order to be able to model the brittle behaviour in the fibre direction.

$$
\begin{cases}d_{1}=0 & \text { if } Y_{d_{1}}<Y_{d_{1}}^{\max } \\ d_{1}=1 & \text { if } Y_{d_{1}} \geq Y_{d_{1}}^{\max }\end{cases}
$$

$Y_{d_{1}}^{\max }$ is the parameter defining the ultimate force in the fibre direction.

The gradual development of both damage $d_{2}$ and $d_{12}$ depends on the tension load as well as on the shear load, which generates the small cracks. The tension/shear coupling during the development of $d_{2}$ and $d_{12}$ is accounted for by the following equivalent thermodynamic force:

$$
Y_{e q}=a \cdot Y d_{2}^{m}+b \cdot Y d_{12}^{n}
$$

where $\mathrm{a}, \mathrm{b}, \mathrm{m}$ and $\mathrm{n}$ are material parameters specifying the tension/shear coupling and $Y_{d_{2}}$ and $Y_{d_{12}}$, the thermodynamic forces associated with $d_{2}$ and $d_{12}$ are written as : $\quad Y_{d_{2}}=\frac{\left\langle\sigma_{2}\right\rangle_{+}^{2}}{2 E_{2}^{0}\left(1-d_{2}\right)^{2}} ; \quad Y_{d_{12}}=\frac{\sigma_{12}^{2}}{2 G_{12}^{0}\left(1-d_{12}\right)^{2}}$

The evolution law for the damage is written as follows:

$$
\begin{aligned}
& d_{2}=\left\langle 1-e^{-\left(Y_{e q}-Y_{0}\right)}\right\rangle_{+} \\
& d_{12}=c . d_{2}
\end{aligned}
$$

where the constant parameter $Y_{o}$ corresponds to the threshold value of the development of $d_{2}$ (which ranges from 0 to 1 ) and $d_{12}$ is proportional with a ratio $c$ to $d_{2}$, since these parameters both describe the effects of the same cracks, which mainly run parallel to the fibres.

After loading has been applied to a $[45]_{8}$ laminate, inelastic strains are observed. These strains may result from the slipping/friction processes occurring between the fibres and matrix as the result of the damage. A kinematic hardening model was used to describe these strains. 
The coupling between the damage and the plasticity is accounted for by the effective stress and the effective strain (Ladevèze, 1992)(Payan et al., 2002), which are written:

$$
\tilde{\sigma}_{12}=\frac{\sigma_{12}}{\left(1-d_{12}\right)} \text { and } \tilde{\varepsilon}_{12}^{p}=\varepsilon_{12}^{p}\left(1-d_{12}\right)
$$

It is assumed that the longitudinal and the transverse stresses, $\sigma_{1}$ and $\sigma_{2}$, do not influence the elastic field domain defined by:

$$
f=\left|\tilde{\sigma}_{12}-X\left(\tilde{\varepsilon}_{12}^{p}\right)\right|-R_{0}
$$

where $R_{0}$ is the initial inelastic strain threshold and $X$ is the hardening parameter.

In the case of unbalanced woven ply reinforced with glass fibres, four tension tests presented in Figure 5 were necessary to identify all the parameters of the damage model. The parameters of the damage model were identified in the tests on $[0]_{8},[90]_{8}$, and $[22]_{8}$ laminates. Those of the hardening model were identified in the test on a [45] laminate.
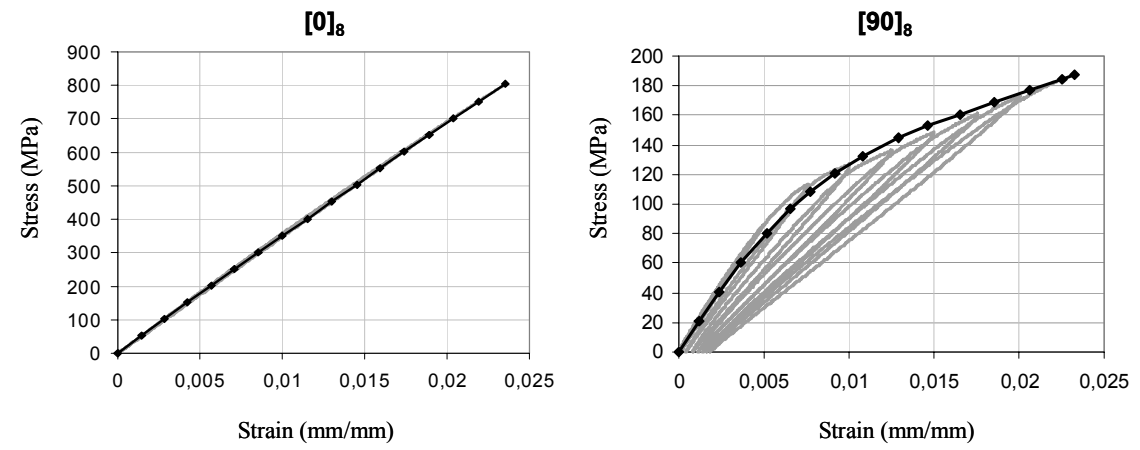

$[45]_{8}$

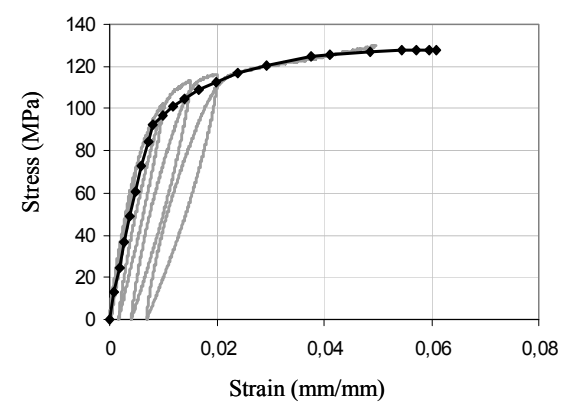

$[22]_{8}$

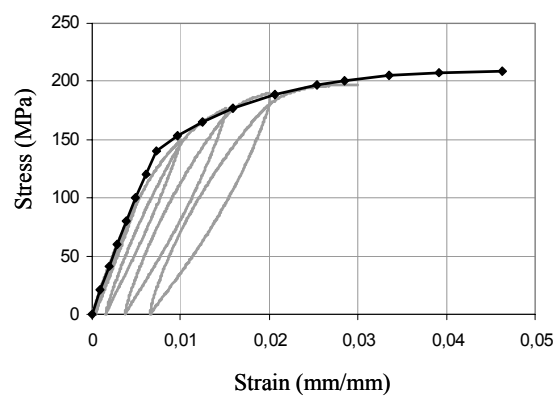

$$
\text { - Exp } \rightarrow \text { Model }
$$

Figure 5. Four tension tests to identify the behaviour of the unbalanced woven ply 


\subsection{Integration into Abaqus}

The implementation of the behavioural laws was performed by writing a UMAT routine. In the global non linear problem solving by Abaqus with the Newton's method, the UMAT routine must update the stresses, the solution-dependant state variables and the Jacobian matrix according to the strains at each step of the incremental calculation. The UMAT routine we developed, described the behaviour of each UD ply. Then, the homogenization was made by Abaqus by using the laminated theory. Plane stress assumption is used and only one Gauss Point is defined in the thickness of each UD ply.

The inputs of the UMAT routine were:

- the parameters of the behavioural model, which are the properties of the woven ply, the parameters of the damage laws and the parameters of the kinematic hardening law,

- the values of the state variables at the previous step, which are the damage variables and the inelastic strains,

- the strains of the increment for which the UMAT routine is called.

The outputs were the stresses and the Jacobian matrix.

The UMAT routine was based on the following algorithm:

1. Calculation of properties of the equivalent UD ply

2. Calculation of the stiffness matrix

3. Estimation of the elastic response

4. Test on the state variables evolution:

- evolution of the damage ?

- evolution of the inelastic strain?

5. Updating of the stresses and the state variables values

6. Checking of the assumptions on the damage and inelastic strain evolution

7. Calculation of the Jacobian matrix.

\section{Application to unbalanced woven ply laminates}

\subsection{The non local approach applied to plates with a hole}

Tension tests were carried out on perforated plates composed of various pre-preg laminates consisting of unbalanced woven Glass/Epoxy ply. The specimens measured $300 \times 45 \times 2.5 \mathrm{~mm}^{3}$. A hole $13 \mathrm{~mm}$ in diameter was drilled in the centre of each plate. It was observed experimentally that the failure of these structures was brittle and due to fibre failure. In the model, the calculations were stopped when the FCV criterion [1] was reached. As each woven ply was taken to be a [0,90] laminate consisting of two UD plies, the failure criterion was assessed on each UD ply 
modelled. Two diameters therefore had to be identified to define the size of both FCVs in the UD ply oriented at $0^{\circ}$ and $90^{\circ}$.

The two UD plies were taken to have the same mechanical properties but not the same thickness, to account for the difference between the proportion of fibres running in the warp and weft directions. The FCVs can also be different between the two directions because the fracture volume may depend on the internal structure of the material (size of yarns, thickness of ply, etc.). Tests were therefore performed on $[0]_{8}$ and $[90]_{8}$ laminates to determine the FCV diameter in the UD ply oriented at $0^{\circ}$ and in the UD ply oriented at $90^{\circ}$. The experimental data were compared with the numerical predictions. The FCV diameters were therefore identified and were both found to measure slightly less than one millimetre. Predictions were then obtained on the other three laminates $[ \pm 18]_{4 S},[15]_{8}$ and (QI) without having to change any of the parameters, which shows that the parameters are intrinsic to the material.

Figure 6 gives the experimental data (-) and the values predicted by the model based on CDM combined with the FCV criterion (- $\$-)$. These results show that the method based on non linear behaviour and the non local criterion accurately predicted the force at failure and the displacement in a plate with a hole, in the case of laminates of several kinds.

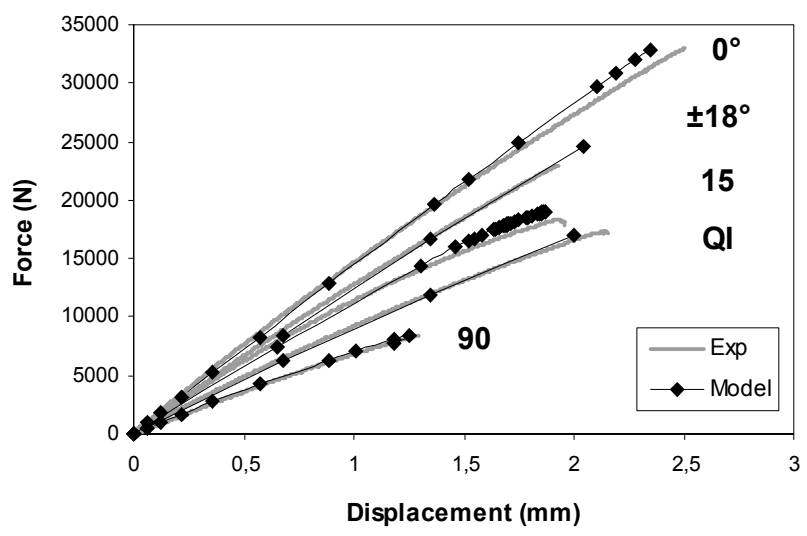

Figure 6. Comparison between experimental data (-) and numerical predictions $(-\downarrow)$ for plates with open hole in the case of various laminates

\subsection{Plates with notches and saw cuts}

The use of the non local criterion was tested in the case of structures with high stress gradients, such as plates with macro-cracks (corresponding to saw cuts) and circular notches. The strength at failure was measured experimentally in several laminates $\left([0]_{8},[90]_{8},(\mathrm{QI})_{8},[ \pm 18]_{4 \mathrm{~s}}\right.$ and $\left.[15]_{8}\right)$ with various stress distributions (plates with a central hole, plates with notches or saw cuts on both sides). Specimen geometry is shown in Figure 7. External dimensions of the plates are the same as 
those of the perforated plates previously described. The notches were circular with a radius of $3 \mathrm{~mm}$. The saw cuts were rectangular, measuring $1 \times 3 \mathrm{~mm}^{2}$.

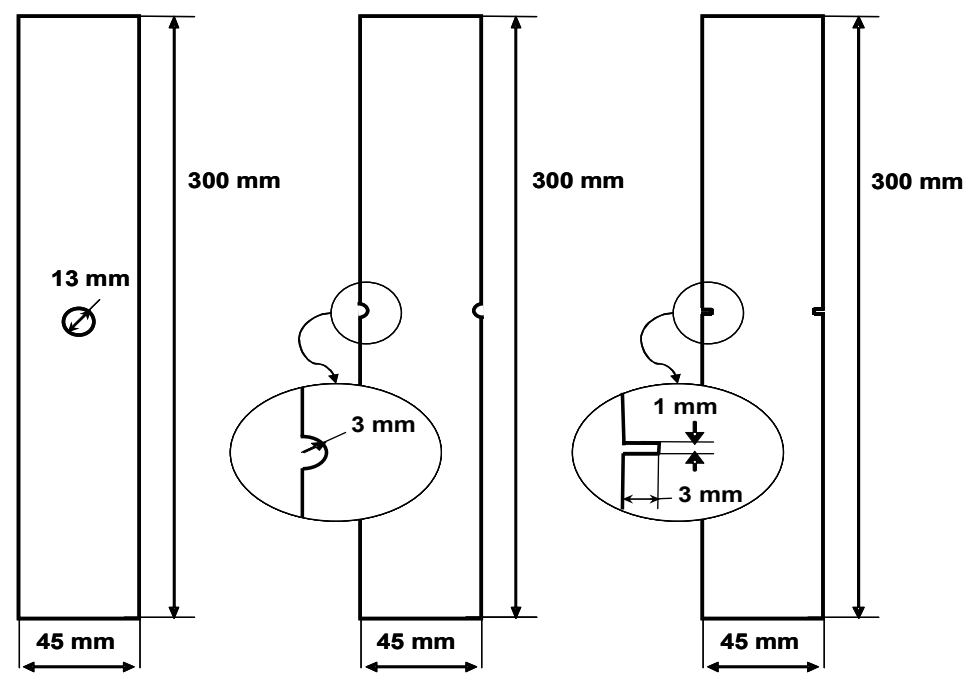

Figure 7. Geometry of the various specimens

The results obtained using the approach presented here (see Figure 8), in which non linear behaviour is combined with the non local failure criterion (CDM model/FCV), matched the experimental data (Exp) quite satisfactorily, even at high stress concentrations. Failure will occur when the failure criterion is reached in an FCV.

\section{Validity of the method}

\subsection{Use of the FCV with an elastic behaviour model}

In this section, a simplified approach is presented, which can be used in a preliminary stage. In this approach, the FCV is used with an elastic behavioural model. The same failure criterion is applied here as that presented above. The behaviour of each ply is taken to be linear elastic and brittle. With this linear behaviour, the computation time and the number of parameters to be identified are greatly reduced. All the parametric values required are the same as those used in the previous approach. The size of the FCV was previously identified, but this could be done if necessary by performing a tension test on a $[ \pm 18]_{4 \mathrm{~s}}$ specimen, for example.

Figure 8 gives results obtained with this method (Elastic/FCV). In the case of $(\mathrm{QI})$ and $[ \pm 18]_{4 \mathrm{~s}}$ laminates, this method gave satisfactory results. In the case of $[0]_{8}$ and $[90]_{8}$ laminates, the results obtained were less accurate because the damage cannot be neglected. In the region of the geometrical singularity, the level of damage 
is very high, which greatly influences the stress distribution. In the last case studied, the $[15]_{8}$ laminate showed strongly non linear overall behaviour. So, the elastic law did not work.
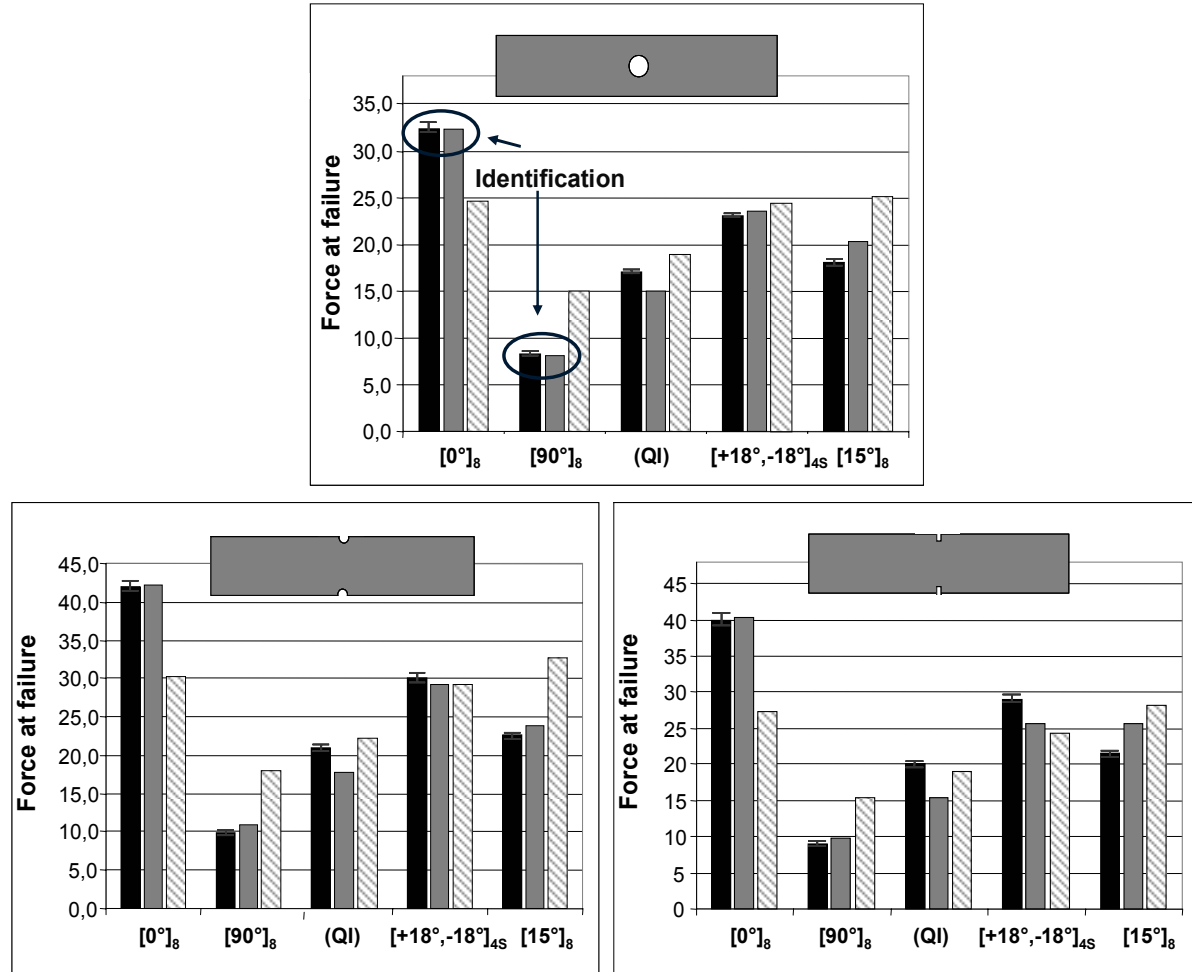

$\square$ Exp $\square$ CDM Model/FCV $\triangle$ Elastic/FCV

Figure 8. Comparisons between tests and numerical predictions in the case of various laminates with high stress gradients (Force at failure in $\mathrm{kN}$ )

The results obtained using a simple approach in which the FCV is combined with an elastic model for quasi-isotropic laminates match the experimental data fairly closely. This easy-to-use approach makes it possible to rapidly predict the failure of a laminated structure. It can be used in industrial contexts where the costs, the number of tests, and the computation time are important factors.

\subsection{Influence of the mesh}

Figure 9 shows another advantage of using a non local criterion. Force at failure is given here versus the number of integration points in the FCV. The reference test 
was a tension test on a $[0]_{8}$ laminate with two saw cuts. The experimentally measured force at failure was $40 \mathrm{kN}$. It can be seen from this figure that the use of the method in which the CDM model is combined with the non local approach yields rapidly converging results, depending on the thinness of the mesh. The meshing element used was of the linear shell type without reduced integration, giving four integration points in each element. The FCV criterion makes it possible to obtain mesh-independent results, even on structures with high stress gradients, which is not the case with most conventional methods, such as those based on characteristic length criteria (Whitney et al., 1976), which can lead to meshdependent problems if there is a stress gradient in the orthogonal direction with respect to the characteristic length direction.

$\left[0^{\circ}\right]$ - plate with saw cut

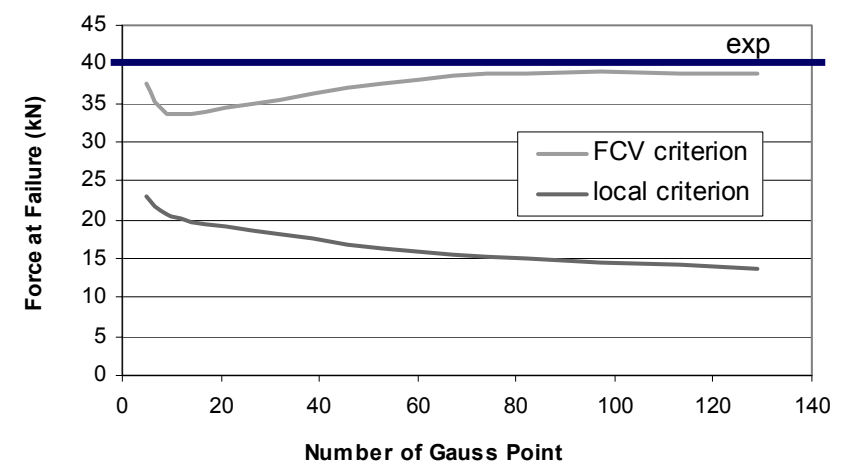

Figure 9. Evolution of the predicted force at failure versus the size of mesh (characterised by the number of Gauss Point in the FCV)

On the other hand, when a local criterion is used, the force at failure depends on the size of the element and does not converge if the solution is singular. It should be noted that with the local criterion, the results do not match the experimental data whatever the size of element tested.

\section{Conclusion}

A CDM model which describes diffuse damage and the inelastic strain evolution was combined here with a simple non local ply scale failure criterion based on a Fracture Characteristic Volume.

This approach was implemented in ABAQUS and used to predict the failure of various types of plies and laminates subjected to stress concentrations. The results obtained matched the experimental data fairly satisfactorily and were found be independent of the meshing characteristics. An extension of this method to fatigue loading conditions is now being developed (Thollon et al., 2009) (Hochard et al., 2010). 
The non-local criterion based on the characteristic volume is also independent of the behavioural model adopted and the type of ply studied. This method was successfully tested in previous studies with linear and CDM behavioural models in the case of laminates with balanced woven plies (Hochard et al., 2007) (Hochard et al., 2009), in that of laminates with unbalanced woven plies in this paper, and in that of laminates with unidirectional plies (Laurin et al., 2006) and other cases (Miot et al., 2009) (Tay et al., 2008).

\section{References}

Ladevèze P., "A damage computational method for composite structures", Computers \& Structures, 1992, vol. 44, p. 79-87.

Wang A.S.D., "Strength, failure, and fatigue analysis of laminates", Engineered Materials Handbook, ASM 1987, 1, p. 236-251.

Reifsnider, K., "Durability and damage tolerance of fibrous composite systems", Handbook of Composites, $2^{\text {nd }}$ ed, Chapman and Hall, 1998, p. 794-809.

Hochard C., Aubourg P-A. and Charles J.-P., "Modelling of the mechanical behaviour of woven-fabric CFRP laminates up to failure", Composites Science and Technology, 2000, vol. 61, p. 221-230.

Bordreuil C., Hochard C., "Finite element computation of woven ply laminated composite structures up to rupture", Applied Composite Material, 2004, vol. 11, $\mathrm{n}^{\circ} 3$.

Hochard Ch., Lahellec N. and Bordreuil C., "A ply scale non-local fibre rupture criterion for CFRP woven ply laminated structures", Composite Structures, 2007, vol. 80, p. 321-326.

Hochard Ch., Miot S., Lahellec N. and al., "Behaviour up to rupture of woven ply laminate structures under static loading conditions", Composites: Part A, 2009, vol. 40, n 8 , p. $1017-1023$.

Miot S., Hochard C. and Lahellec N., "A non-local criterion for modelling unbalanced woven ply laminates with stress concentrations", Composite Structures, In Press, doi:10.1016/j.compstruct.2009.11.019

Périé, J.N., Leclerc, H., Roux, S., Hild F., "Digital image correlation and biaxial test on composite material for anisotropic damage law identification", 2009 International Journal of Solids and Structures, vol.46, n 11-12, p. 2388-2396.

Withney J., Nuismer R., "Strain gradient in composite laminate structure", Journal of composite materials, 1976, 35, p. 733-735.

Thollon Y., Hochard C., "A general damage model for woven fabric composite laminates up to first failure", Mechanics of Materials, 2009, vol. 41, n 7, p. 820-827.

Ladevèze P., Allix O., Deü J.F. et al., "A mesomodel for localisation and damage computation in laminates", Comput. Methods Appl. Mech. Engrg, 2000, vol. 183, p. 105-122.

Ladevèze P. and Lubineau G., "On a damage mesomodel for laminates: micro-meso relationships", Composites Science and Technology, 2001, vol. 61, n 15. 
104 EJCM - 19/2010. Giens 2009

Payan J. and Hochard C., "Damage modelling of laminated carbon/epoxy composites under static and fatigue loadings", International Journal of Fatigue, vol. 24, n 2-4, 2002.

Hochard C., Thollon Y., "A generalized damage model for woven ply laminates under static and fatigue loading conditions", Int. Journal of Fatigue, 2010, vol. 32, n 1, p. 158-165.

Laurin F., Carrere N. and Maire J.F., "Multiscale progressive failure approach for strength analysis of high gradient composite structures", Proceedings of ECCM12 Biarritz (France), 2006.

Tay, T.E., Liu, G., Tan, V.B.C., Sun, X.S., Pham, D.C. "Progressive failure analysis of composites", Journal of Composite Materials, 2008, vol.42, n 18, p. 1921-1966. 